\title{
AN ORDERING ON GREEN'S FUNCTION AND A LYAPUNOV-TYPE INEQUALITY FOR A FAMILY OF NABLA FRACTIONAL BOUNDARY VALUE PROBLEMS
}

\author{
JAGAN MOHAN JONNALAGADDA
}

\begin{abstract}
In this article, we consider a family of two-point Riemann-Liouville type nabla fractional boundary value problems involving a fractional difference boundary condition. We construct the corresponding Green's function and deduce its ordering property. Then, we obtain a Lyapunov-type inequality using the properties of the Green's function, and illustrate a few of its applications.
\end{abstract}

Mathematics subject classification (2010): 34A08, 39A10, 39A12, 34B15.

Keywords and phrases: Fractional order, backward (nabla) difference, boundary value problem, Green's function, Lyapunov-type inequality, nabla Mittag-Leffler function.

\section{REFERENCES}

[1] T. Abdeljawad And F. M. Atici, On the definitions of nabla fractional operators, Abstr. Appl. Anal., Art. ID 406757, 2012.

[2] K. Ahrendt, L. Castle, M. Holm And K. Yochman, Laplace transforms for the nabladifference operator and a fractional variation of parameters formula, Commun. Appl. Anal. 16, 3 (2012), 317-347.

[3] G. A. Anastassiou, Nabla discrete fractional calculus and nabla inequalities, Math. Comput. Modelling 51, 5-6 (2010), 562-571.

[4] F. M. Atici And P. W. Eloe, Discrete fractional calculus with the nabla operator, Electron. J. Qual. Theory Differ. Equ., Special Edition I, 3 (2009), 12 pp.

[5] F. M. Atici And P. W. Eloe, Two-point boundary value problems for finite fractional difference equations, J. Difference Equ. Appl. 17, 4 (2011), 445-456.

[6] A. BRackins, Boundary Value Problems of Nabla Fractional Difference Equations, Ph.D. Thesis The University of Nebraska-Lincoln, 2014.

[7] M. Bohner And A. Peterson, Dynamic Equations on Time Scales, Birkhäuser, Boston, 2001.

[8] A. ChIDOUh AND D. F. M. TORRES, Existence of positive solutions to a discrete fractional boundary value problem and corresponding Lyapunov-type inequalities, Opuscula Math. 38, 1 (2018), 31-40.

[9] P. W. Eloe, J. W. Lyons And J. T. NeugebaueR, An ordering on Green's functions for a family of two-point boundary value problems for fractional differential equations, Commun. Appl. Anal. 19, (2015), 453-462.

[10] R. A. C. Ferreira, Some discrete fractional Lyapunov-type inequalities, Fract. Differ. Calc. 5, 1 (2015), 87-92.

[11] K. Ghanbari And Y. Gholami, New classes of Lyapunov type inequalities of fractional $\Delta$ difference Sturm-Liouville problems with applications, Bull. Iranian Math. Soc. 43, 2 (2017), 385-408.

[12] Y. Gholami And K. Ghanbari, Coupled systems of fractional $\nabla$-difference boundary value problems, Differ. Equ. Appl. 8, 4 (2016), 459-470.

[13] C. Goodrich, On a fractional boundary value problem with fractional boundary conditions, Appl. Math. Lett. 25, 8 (2012), 1101-1105.

[14] C. Goodrich And A. C. Peterson, Discrete Fractional Calculus, Springer, Cham, 2015.

[15] C. GoodRICH, Solutions to a discrete right-focal fractional boundary value problem, Int. J. Difference Equ. 5, 2 (2010), 195-216. 
[16] A. IKram, Green's Functions and Lyapunov Inequalities for Nabla Caputo Boundary Value Problems, Ph.D. Thesis - The University of Nebraska-Lincoln, 2018.

[17] JaGAN MOHAN JonnalagadDa, Analysis of a system of nonlinear fractional nabla difference equations, Int. J. Dyn. Syst. Differ. Equ. 5, 2 (2015), 149-174.

[18] Jagan Mohan JonnalagadDa, Discrete fractional Lyapunov-type inequalities in nabla sense, Dyn. Contin. Discrete Impuls. Syst. Ser. A Math. Anal., Manuscript submitted for publication.

[19] Jagan Mohan Jonnalagadda, Lyapunov-type inequalities for discrete Riemann-Liouville fractional boundary value problems, Int. J. Difference Equ. 13, 2 (2018), 85-103.

[20] Jagan Mohan Jonnalagadda, On two-point Riemann-Liouville type nabla fractional boundary value problems, Adv. Dyn. Syst. Appl. 13, 2 (2018), 141-166.

[21] W. G. Kelley And A. C. Peterson, Difference Equations, Academic Press, San Diego, 2001.

[22] A. A. Kilbas, H. M. Srivastava and J. J. Trujillo, Theory and Applications of Fractional Differential Equations, North-Holland Mathematics Studies, Amsterdam, 2006.

[23] I. Podlubny, Fractional Differential Equations, Academic Press, San Diego, 1999. 